\title{
Daily gridded evapotranspiration estimates for Australia
}

\author{
$\underline{\text { A.J. Frost }}^{\mathrm{a}}$, A. Ramchurn ${ }^{\mathrm{b}}$, A. Oke \\ ${ }^{a}$ Bureau of Meteorology, 300 Elizabeth Street, Sydney, Australia \\ ${ }^{b}$ Bureau of Meteorology, 700 Collins Street, Melbourne, Australia \\ Email: andrew.frost@,bom.gov.au
}

\begin{abstract}
There are various Evapotranspiration (ET) estimates/products available for agricultural, engineering, and operational purposes including (a) Evaporative demand (potential ET) and actual evapotranspiration; (b) FAO56 Reference Evapotranspiration from crops and (c) Evaporation from reservoirs, rivers and farm dams.

The Bureau of Meteorology currently provides daily national gridded actual and potential landscape evapotranspiration products via the Australian Landscape Water Balance website www.bom.gov.au/water/landscape. However, while the Bureau produces Daily FAO56 reference ET at 486 automatic weather station sites across Australia (through www.bom.gov.au/watl/eto), there is no equivalent gridded daily product. In terms of evaporation from reservoirs, rivers and farm dams; the Bureau measures Class-A pan evaporation records at 179 locations across the country, and has used these observations over the period 1975-2005 to produce a static set of monthly, seasonal and annual average maps (www.bom.gov.au/jsp/ncc/climate averages/evaporation). Again, there is no equivalent daily gridded product equivalent to the pan evaporation, or perhaps more importantly a product specifically designed for estimation of evaporation from water bodies. Further, in both of these cases the observational sites locations can often be far from the location of interest, and interpolation of these data, as done to produce the maps, can be strongly biased due to local meteorological effects.
\end{abstract}

This paper evaluates six daily gridded products including (a) synthetic pan evapotranspiration for operational demand/evaporation monitoring and planning (PenPan), (b) FAO56, (c) ASCE tall crop Reference evapotranspiration for irrigation/agricultural purposes, (d) Penman (as applied by Donohue), (e) Morton areal estimates of ET, and (f) Morton's shallow lake evaporation. The input datasets used to derive these products are compared against available data, and interim (long wave radiation) and derived variables (class A pan evaporation) are compared against observations where available. These products are compared relatively and with available data such as the average maps and for a single site (Fig. 1).

The comparisons show that gridded data inputs were not systematically biased with respect to station climate inputs (temperature, solar radiation, $2 \mathrm{~m}$ wind) as expected as these data are used in generating the gridded products used. Biases were found in the approach used in FAO56 to transform $10 \mathrm{~m}$ observations to $2 \mathrm{~m}$ wind observations; while the gridded wind $2 \mathrm{~m}$ product used circumvents this issue. Gridded $2 \mathrm{~m}$ wind products are recommended to be used in place of transformed $10 \mathrm{~m}$ wind. Secondly, the PenPan estimate of pan evaporation correctly captured temporal trends (following Donohue) but was biased positively in some locations with further investigation required to understand why this differs from Donohue. Spatial plots of annual maps and site temporal statistics demonstrate the differences between the different methods tested. Further testing is required to evaluate and demonstrate the value of using satellite derived vegetation indices (MODIS as available operationally in the Bureau vs AVHRR used in Donohue). However, the estimates of ET (FAO56, ACSE tall, Morton shallow lake and PenPan) can be implemented immediately on the proviso that there are some differences with pan data, and these will be investigated, with products expected to improve over time with improved inputs and algorithms.

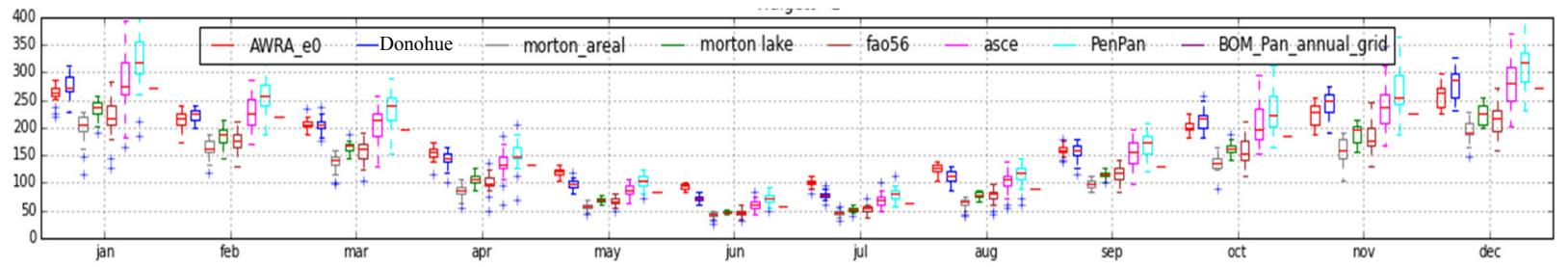

Figure 1. Boxplot of Walgett 1990-2011 monthly ET (mm/month) according to tested methods.

Keywords: PenPan, FAO56, ASCE tall, Penman, Morton areal, gridded, evapotranspiration, evaporation 
Frost, Ramchurn and Oke. Daily gridded evapotranspiration estimates for Australia

\section{INTRODUCTION}

There are various ET products useful for agricultural, engineering, and operational purposes including:

1. Synthetic pan estimates: for comparison with pan observations which are used in design/operations

2. Reference Evapotranspiration from crops: short crop FAO56 and ASCE tall crop for irrigation/agricultural planning and realtime management purposes

3. Evaporative demand (potential ET) for identification of trends in PET and using in hydrological models for use in calibration and driving of hydrological models

4. Shallow lake evaporation: for reservoirs/farm dams reservoirs, rivers and farm dams

See McMahon et al. (2013) for a comprehensive review of methods for estimating these terms.

The Bureau currently provides a national daily gridded potential and actual ET via the Australian Landscape Water Balance website (www.bom.gov.au/water/landscape), according to the AWRA-L water balance model (see Viney et al., 2015; Frost, Ramchurn and Smith, 2016) that uses Penman (1948) potential ET formulation. This potential evapotranspiration is then used to calculate actual ET based on the model water balance and vegetation growth model dynamics based on the assumptions used in the model in particular that the landscape consists of either deep rooted (trees) or shallow rooted (grass) hydrological response. This modelled value of PET is not necessarily representative or appropriate for use with crop growth models for example; where specific crops not equivalent to those conceptualized in AWRA-L are in place.

The Bureau produces Daily FAO56 reference ET at 486 Automatic Weather Station (AWS) sites across Australia through www.bom.gov.au/watl/eto (Webb, 2010) with estimates available back to 2009. Given the sparsity of AWS sites, farmers and irrigators may need to rely on station records that can be hundreds of kilometres away; therefore these values may not be useful to the user.

The Bureau measures Class A pan evaporation across Australia (currently locations shown in Fig. 2(a)). This point pan data is used to estimate evaporation for reservoirs and also in the estimation of demand relationships for planning and operation by water authorities. Long term average monthly, seasonal and annual maps (www.bom.gov.au/jsp/ncc/climate averages/evaporation/index.jsp) are provided by the Bureau based on this data. These averages are used in some cases for design of infrastructure including dams, stormwater harvest and effluent reuse. However, these estimates can be biased where there is no long term coverage of pan data and further may not be fit for purpose as they are pan estimates rather than for open water. Finally, the BoM has also published temporally averaged maps of potential ET calculated according to the Morton areal estimate (see www.bom.gov.au/jsp/ncc/climate averages/evapotranspiration/index.jsp and Fig 2(b); Chiew et al., 2002; Wang et al., 2001). These estimates are now outdated. Overall, gridded daily estimates of FAO56, pan and potential evaporation using these inputs are not available operationally from the Bureau of Meteorology.
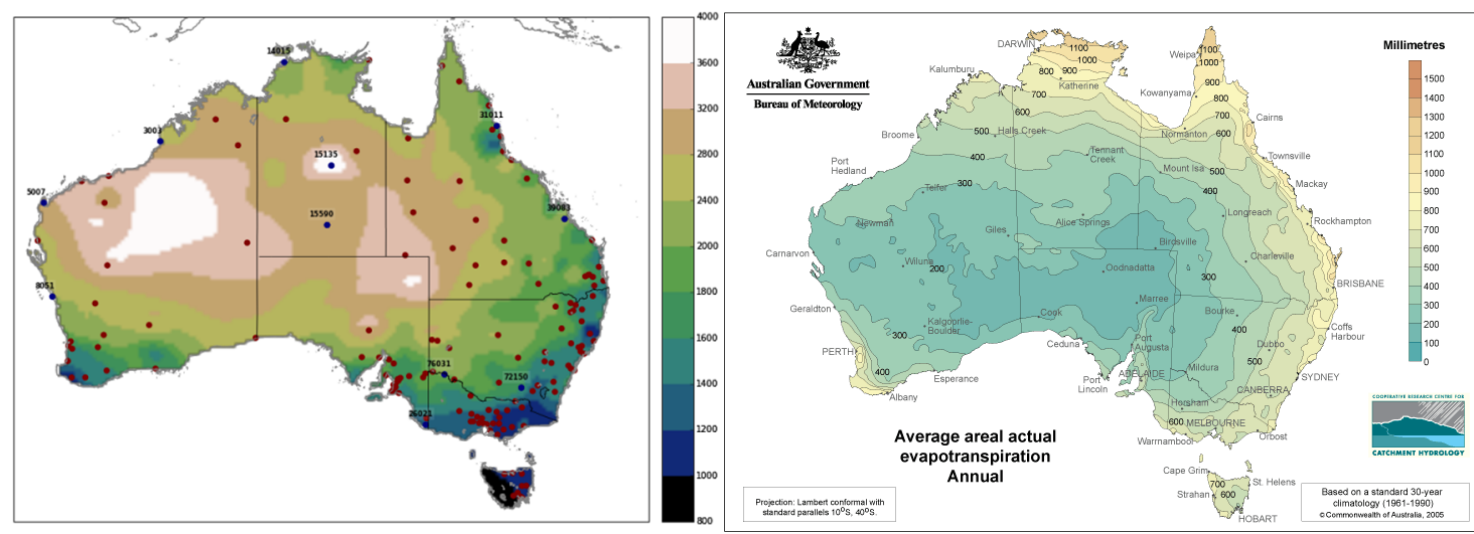

Figure 2. BoM (a) pan locations and average annual pan evaporation (mm/yr) over 1975-2005 and (b) average annual Morton areal ET over 1961-1990

In addition to those listed above, many other estimates are also possible that do not rely on the validity of internal vegetation and water balance dynamics of the hydrological model. Donohue et al. (2010) provides a comparison of five PET estimates ((i) Penman; (ii) Priestley-Taylor; (iii) Morton point; (iv) Morton areal; and (v) Thornthwaite) using satellite based vegetation indices and interpolated wind data, and found the Penman formulation to be the most reasonable estimation of potential evaporation dynamics. It is noted that study used Advanced Very High-Resolution Radiometer (AVHRR) satellite based estimates of albedo and 
vegetation fraction cover (Donohue et al., 2008), and synthetic estimates using these inputs reproduced trends in observed pan data. Moreover, the Penman formulation was shown to produce the most reasonable estimation of potential evaporation dynamics, reproducing an expected inverse relationship with precipitation trends, and also showing sensitivity to observed changes in albedo and wind. Further daily spatially interpolated wind data was used (McVicar et al., 2008), and that data has previously been shown to reproduce the wind stilling trend observed within Australia/globally; whereas the reanalysis products (outputs of global atmospheric models using assimilated observations) available at the time did not.

SILO (Jeffrey et al., 2001; DSITI Qld: www.longpaddock.qld.gov.au/silo/data available.html) datasets currently provide national gridded daily FAO56 estimates among other ET products including six estimates tailored for the agricultural and hydrological audience: FAO56 short crop and ASCE tall crop estimates; and Morton's actual, potential, wet and lake estimates. These products have recently been made freely available to current registered users.

It is noted that the SILO FAO56/ASCE product relies on a constant wind value of $2 \mathrm{~m} / \mathrm{s}$ nationally; rather than a climatology derived from the McVicar et al. (2008) dataset as used in AWRA-L, transformed $10 \mathrm{~m}$ to $2 \mathrm{~m}$ observations as used in the BoM point estimates at weather stations, or interpolated gridded $2 \mathrm{~m}$ observations as used in Donohue et al. (2010; herein referred to as Donohue). Further SILO solar radiation estimates based on observed cloud oktas and hours of sunshine duration following the approach of (Zajaczkowski et al., 2013). This approach was devised towards utilizing observed BoM point data available prior to the 1990, after which BoM supply gridded satellite derived estimates of solar radiation (see section 2). AWRA-L uses daily climatologies derived from this satellite data prior to 1990; BoM point FAO56 uses the gridded satellite data, while Donohue uses a model calculated value of incoming solar radiation.

\section{METHOD AND DATA}

The paper first compares input forcing including wind, temperature and solar radiation data/estimates according to observed data over the period 1990-2015 at BoM site locations that have an observed pan estimate. This subset of BoM climate sites is used towards understanding outputs at these locations and demonstrating that the derived outputs follow the mean, variability and trends observed. The time period 1990-2015 was used as this covers the period of available satellite data for solar radiation and daily gridded wind. Derived intermediate variables including pan estimates of ET (using PenPan methodology; see below) and longwave radiation for the different formulations (Morton and various versions of Penman) are compared to the observed over the shorter period 1990-2011 (over which satellite data for solar radiation and vegetation indices were both available). After assessing the gridded climate inputs, differences between the various proposed products are assessed and explained, comparing to current products where possible (eg. BoM point FAO56 and Morton areal maps, AWRA based estimates).

Estimates: The following new gridded estimates are compared

1. Synthetic pan evaporation PenPan (Rotstayn et al., 2006) as applied by Donohue

2. FAO56 (Allen et al., 1998) and ASCE tall crop (Walter et al., 2001) evapotranspiration

3. Penman potential ET as applied by Donohue

4. Morton's areal ET

5. Morton's shallow lake evaporation

The outputs of these methods are compared nationally at a selected location for understanding purposes.

Climate and vegetation forcing: The $\sim 5 \mathrm{~km}$ by $5 \mathrm{~km}$ gridded daily climate AWAP datasets (Jones et al., 2007) produced by the Bureau (see www.bom.gov.au/jsp/awap) are used as forcing inputs for all trialed gridded methods used here. This includes interpolated precipitation, maximum and minimum temperature and vapour pressure, along with daily solar radiation estimate based on biased corrected satellite data. In addition we also use interpolated gridded daily wind run data (McVicar et al., 2008). AVHRR Satellite based estimates of albedo and vegetation fraction are used for the Penman estimate as per Donohue.

Evaluation: Local forcing climate variables (wind speed run, air temperature) were extracted from the BoM database to assess the accuracy of the gridded datasets at the selected pan locations. Of the 177 possible BoM Class A Pans sites, 113 have at least 5 years of pan data and are used for comparing to the PenPan estimate (Fig. 2(a) shows locations). 10m wind was extracted where available (although not coincident with the pan locations) for evaluation of the transformation to $2 \mathrm{~m}$ used in the current BoM FAO56 point implementation. Short wave radiation was extracted for 14 sites available nationally (where there was at least 5 years of data) for comparison to gridded estimates. Long wave radiation was extracted at the 11 sites available nationally to compare against the different model implementations. 


\section{RESULTS AND DISCUSSION}

Relative bias and $\mathrm{R}^{2}$ (coefficient of determination) are used for comparison purposes between observed data and the available gridded estimates. For comparison purposes the statistics of the transformaed $10 \mathrm{~m}$ to $2 \mathrm{~m}$ value, and static $2 \mathrm{~m} / \mathrm{s}$ field and climatology are also provided as they represent that as used in SILO FAO56 and AWRA-L currently (R2 NA for constant values). Box plots of relative bias and $\mathrm{R}^{2}$ are presented in Fig 3. The relative bias statistics for solar temperature and windspeed are plotted spatially in Fig 4.

(a) ${ }^{1}$

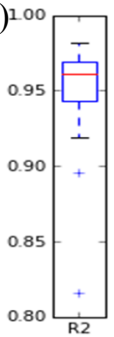

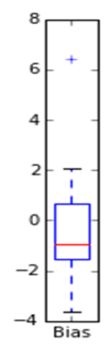

(b)

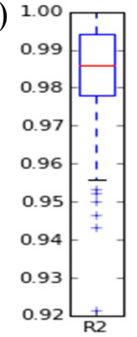

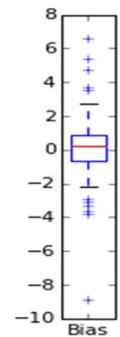
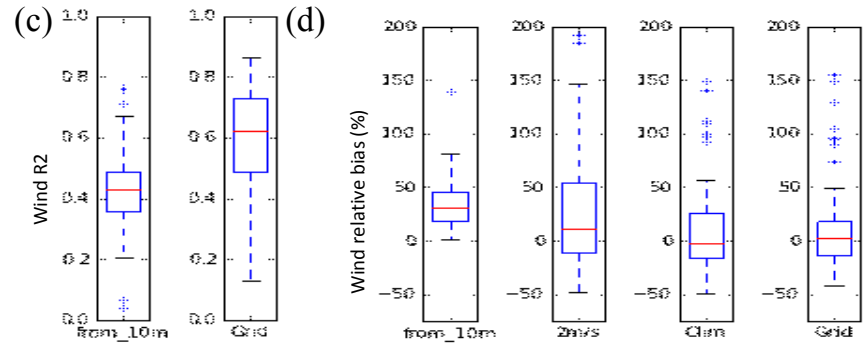

Figure 3. Boxplots of coefficient of determination $\left(\mathrm{R}^{2}\right)$ and relative bias (\% Bias) for daily gridded (a) solar radiation, (b) average temperature, and (c) $\mathrm{R}^{2}$ and (d) bias for differing estimates of $2 \mathrm{~m}$ wind including $10 \mathrm{~m}$ transformed, $2 \mathrm{~m} / \mathrm{s}$ average $(2 \mathrm{~m} / \mathrm{s})$, climatology (Clim), and the daily grids (Grid) of McVicar et al. (2008).
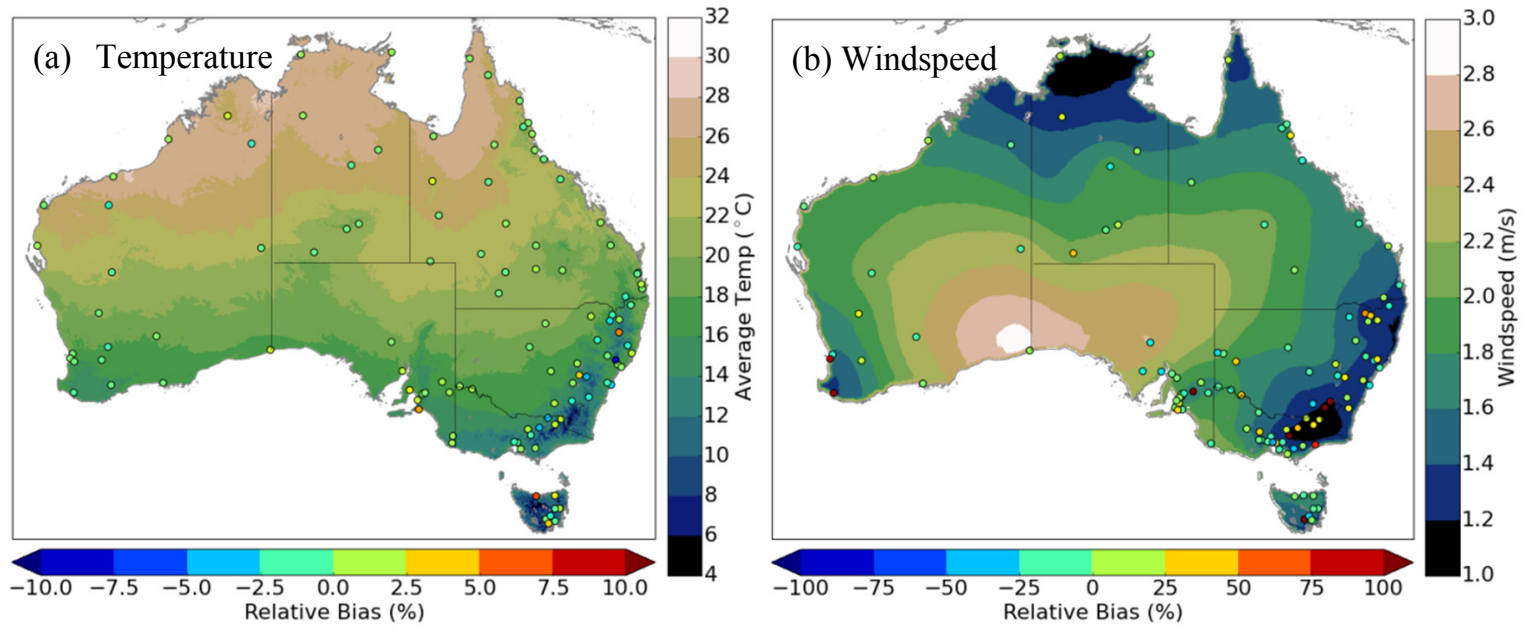

Figure 4. Spatial plots of relative bias (\%) of gridded (a) temperature and (b) wind.

The gridded solar radiation shows a high median $\mathrm{R}^{2}$ value $(0.96)$ and low bias (Fig 3(a)). The low bias is expected as the satellite data used is calibrated/debiased according to these observations periodically. Similarly, average temperature shows high median $\mathrm{R}^{2}$ and low bias (Fig 3(b)). This again is expected due to using site data in interpolation and the relativley high density of temperature observations nationally and relatively lower spatial variability. It appears some higher elevation areas inland are undrestimated (Victorian alps), and that some coastal sites may be overestimated (Fig 4(a)). In terms of $2 \mathrm{~m}$ wind the $\mathrm{R}^{2}$ of the gridded data is higher, and the bias is lower, than that of the FAO56 transformed 10m data (Fig 3(c)) although the data sites and period lengths are not directly comparable. Fig 4(b) shows that the gridded data overestimates in some coastal Western Australia areas along with the Victorian/NSW alps that tend to be in low climatological average wind areas. The $10 \mathrm{~m}$ transformed wind is $30 \%$ over the observed $2 \mathrm{~m}$ data at the median value (Fig 3(d)). The gridded data based on $2 \mathrm{~m}$ observations best produces the observed $2 \mathrm{~m}$ data (as it was used in interpolation), although there is some sites with high bias (e.g. 150\%) presumably due to nearby locations with higher values being weighted strongly in the spline knotting approach used.

The gridded wind and temperature biases were investigated further stratifying the bias values into airport (containing airport, aero, or RAAF in the name), lakes (containing lake/dam/reservoir in the name) and all other pan sites (Fig 5(a)). There appear to be some small temperature biases for these locations, although the reasons for this are currently unclear. To understand the positive bias in the transformed $10 \mathrm{~m}$ to $2 \mathrm{~m}$ data, the data was viewed for a single site (Fig 5(b) Halls Creek in North Eastern WA). This site was investigated as it showed a high bias and an unusual shift in relationship when the two timeseries were plotted. This scatter plot shows two clouds of data following a linear pattern. In looking at the assocated site data, this site was moved from a $10 \mathrm{~m}$ anemometer to an $\sim 6 \mathrm{~m}$ anemometer on $10 / 10 / 2006$, so use of the data assuming a $10 \mathrm{~m}$ observation will bias estimates downwards. The logarithmic wind empirical transform used is nominally for a 
grassed area $(0.12 \mathrm{~m})$ or similar assuming neutral stability; neither of which conditions are generally satisfied, and according to the blue $10 \mathrm{~m}$ shaded data compared to the transform line results in an overstimate in the order of $50 \%$ for $200 \mathrm{~km} /$ day observed at $10 \mathrm{~m}$. The effect of using the different wind products possible (converted $10 \mathrm{~m}$ data, $2 \mathrm{~m} / \mathrm{s}$ average, climatology and daily gridded $2 \mathrm{~m}$ ) to drive FAO56, compared to point observed $2 \mathrm{~m}$ is shown in Fig 6(a) and (b). The transformed $10 \mathrm{~m}$ data causes a positive bias, while the other static products are reasonable estimates in terms of bias, the gridded $2 \mathrm{~m}$ product provides the best estimate overall. Fig 7(a) shows the relative difference in terms of FAO56 estimate when the 10m transformed point data is used, rather than $2 \mathrm{~m}$ gridded wind, with the gridded $2 \mathrm{~m}$ estimate lower than that currently produced.
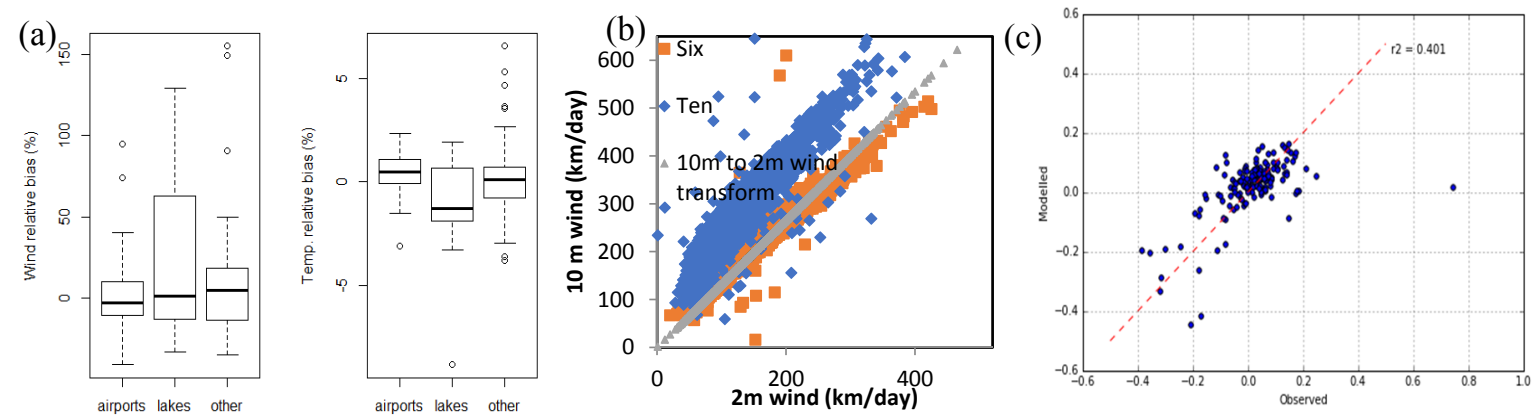

Figure 5. (a) Boxplots of Relative Bias for daily gridded wind and average temperature stratified according into lakes, airports or other locations; (b) site 2012 Halls Creek WA $2 \mathrm{~m}$ vs FAO56 10m wind ( $6 \mathrm{~m}$ and $10 \mathrm{~m}$ obs taken) and $10 \mathrm{~m}$ to $2 \mathrm{~m}$ transform line; and (c) observed annual Pan vs. modelled PenPan trend ( $\mathrm{mm} / \mathrm{mth})$
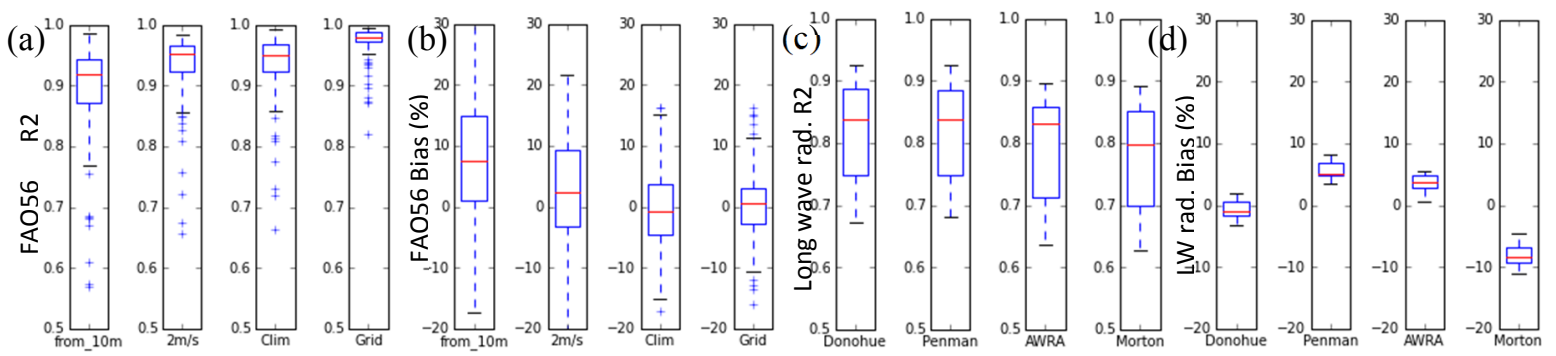

Figure 6. (a) R2 and (b) bias of FAO56 ET using $10 \mathrm{~m}$ transformed, $2 \mathrm{~m} / \mathrm{s}$ average ( $2 \mathrm{~m} / \mathrm{s})$, climatology (Clim), and the daily wind grids (Grid) of McVicar et al., (2008) compared to AWS based estimates; and (c) R2 and (d) bias of Long wave radiation using Donohue, Penman original, AWRA modified Penman, and Morton.
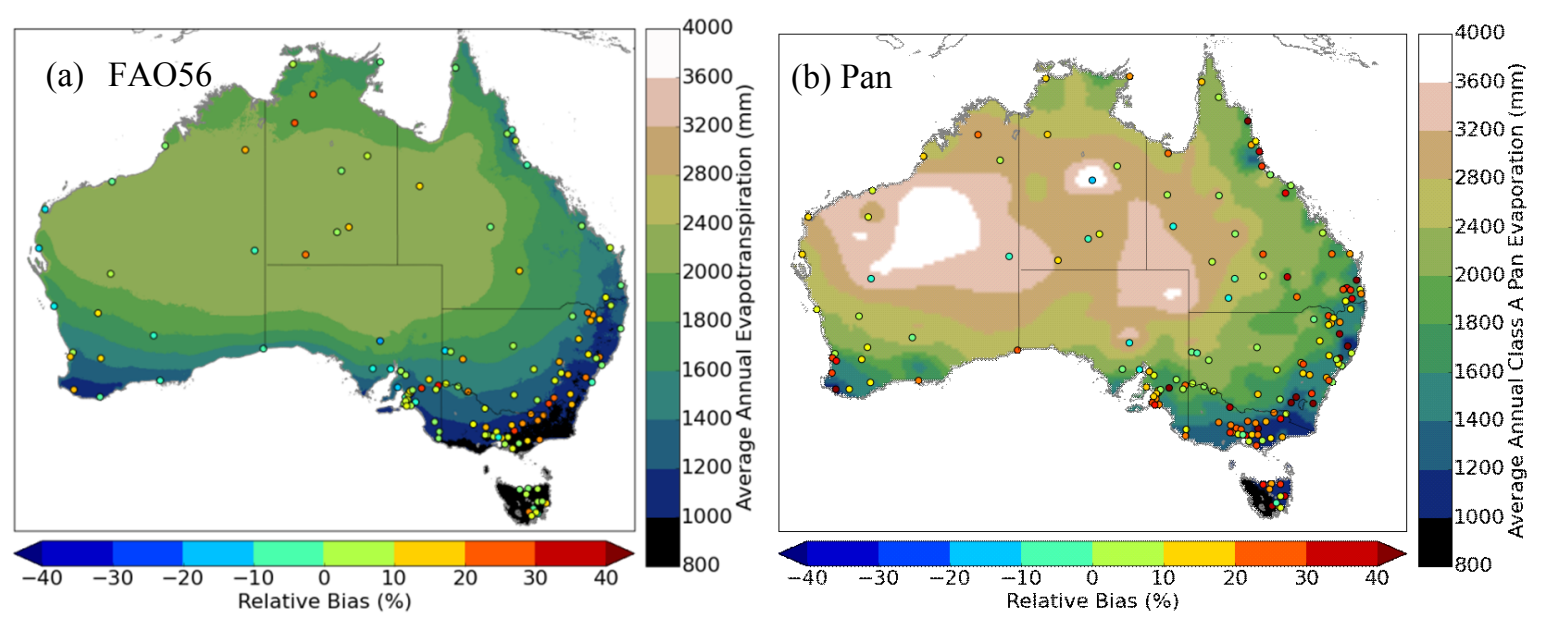

Figure 7. Relative bias of (a) FAO56 using daily 10m transformed wind vs $2 \mathrm{~m}$ gridded; (b) PenPan against Pan

Following Donohue, trends in pan are reasonably reproduced (Fig 5(c)); noting the outlier site 38003 has been identified previously. However, contrasting Donohue PenPan estimates are biased positively overall (median 15\%) compared to pan records, with a map of biases plotted in Fig 7(b), rather than approximately zero when comparing all monthly data across all sites. This is possibly due to differing periods used in evaluation and the use of solar radiation as an input here. We trialed use of the Donohue method for calculation of incoming solar radiation and that further increased the bias, although marginally improving $\mathrm{R}^{2}$ 
(not shown). Further work is required to understand these differences and reduce the bias. Further biases may be reduced by use of updated PenPan methods such as that introduced by Lim et al. (2016).

Net radiation is one of the key components driving evapotranspiration; with incoming solar radiation, surface albedo, and surface emissivity affecting this balance. Penman as originally formulated assumed albedo is 0.05 for open water, and surface emissivity is 1 . Donohue estimates albedo and surface emissivity based on satellite estimated albedo and vegetation fraction. Morton uses a surface emissivity of 0.97 for water and 0.92 for land surfaces, and modulates the average albedo using sunshine hours and elevation.

To evaluate the importance of surface emissivity, the net outgoing longwave radiation component estimation methods (not influenced by albedo) were assessed. AWRA-L uses a method close to that of Penman, except for atmospheric emissivity for clear skies, which uses Brutsaert (1975) rather than Brunt (1932). Morton's formulation additionally makes direct use of sunshine hours and elevation. In all cases tested here, incoming solar radiation was estimated according to satellite derived grids. A comparison of the methods with available longwave radiation records at 11 locations is presented in Fig. 6(c) and (d). The Donohue use of vegetation fraction decreases bias (otherwise slightly positive) compared to Penman. Further the AWRA-L method is also an improvement in terms of bias over Penman, and does not reduce $\mathrm{R}^{2}$ significantly compared to Donohue. Morton estimate is biased negatively and to a greater extent than the other methods detailed.

Spatial plots of annual average values are presented in Fig. 8(a)-(f) for the various methods trialed. Their differences to current BoM gridded average products are also presented (Fig. 8(g) and (h)). Finally, a difference plot is presented for Morton areal using albedo as input (as per Donohue), this shows a marked decrease in ET in central Australia. Monthly boxplots of the different methods are plotted in Fig. 1 for a single site. All other sites are available on request.

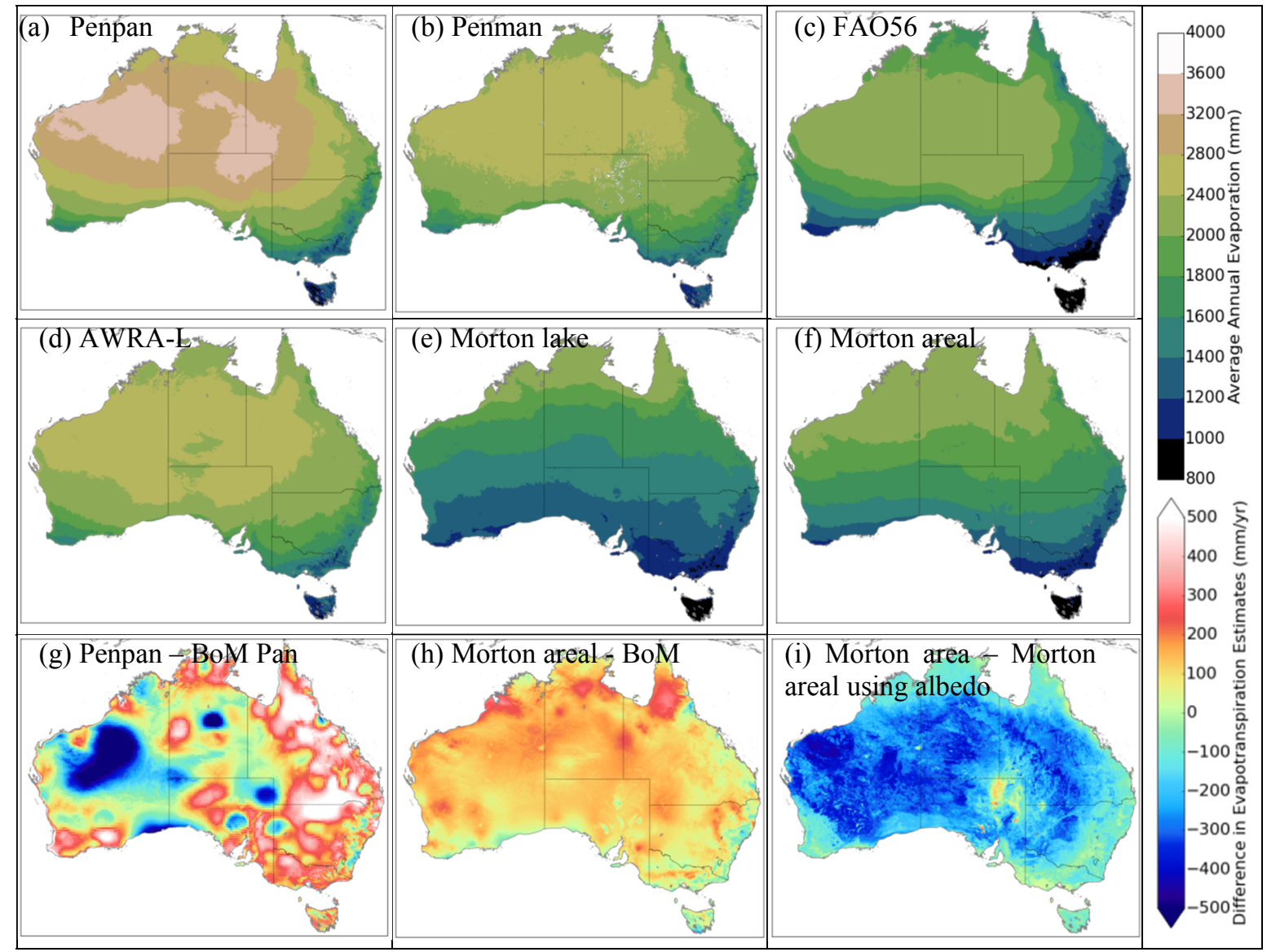

Figure 8. 1990-2011 Annual mean ET (mm/yr)) (a) PenPan, (b) Penman, (c) FAO56, (d) AWRA-L Penman, (e) Morton lake, (f) Morton areal. Difference plots of (g) BoM Pan (1975-2005) and Modelled PenPan, (h) BoM (1961-1990) and modelled Morton areal; and (i) Morton areal using vegetation indices and Morton areal without.

\section{CONCLUSIONS AND RECOMMENDATIONS}

This paper evaluates six daily gridded ET products and the input data used to derive them. The comparisons show that gridded data inputs were not systematically biased with respect to station climate inputs (temperature, solar radiation, $2 \mathrm{~m}$ wind) as expected as these data are used in generating the gridded products 
Frost, Ramchurn and Oke. Daily gridded evapotranspiration estimates for Australia

used. Biases were found in the approach used in FAO56 to transform $10 \mathrm{~m}$ observations to $2 \mathrm{~m}$ wind observations; while the gridded wind $2 \mathrm{~m}$ product used circumvents this issue. It is recommended gridded $2 \mathrm{~m}$ wind products are used in place of transformed $10 \mathrm{~m}$ wind. Secondly, the PenPan estimate of pan evaporation correctly captured temporal trends (following Donohue) but was biased positively in some locations with further investigation required to understand why this differs from Donohue. Spatial plots of annual maps and site temporal statistics demonstrate the differences between the different methods tested. Further testing is required to evaluate and demonstrate the value of using satellite derived vegetation indices (MODIS as available operationally in the Bureau vs AVHRR used in Donohue). However, the estimates of ET (FAO56, ACSE tall, Morton shallow lake and PenPan) can be implemented immediately on the proviso that there are some differences with pan data, and these will be investigated, with products expected to improve over time with improved inputs and algorithms.

\section{REFERENCES}

Allen, R.G., Pereira, L.S., Raes, D., Smith, M. (1998). Crop evapotranspiration: Guidelines for computing crop requirements. Irrig. Drain. Pap. No. 56, FAO 300. doi:10.1016/j.eja.2010.12.001

Brunt, D. (1932). Notes on radiation in the atmosphere. I. Q. J. R. Meteorol. Soc. 58, 389-420. doi:10.1002/qj.49705824704

Brutsaert, W. (1975). On a derivable formula for long-wave radiation from clear skies. Water Resour. Res. 11, 742-744. doi:10.1029/WR011i005p00742

Chiew, F., Wang, Q., Mcconachy, F., James, R., Wright, W., Dehoedt, G. (2002). EVAPOTRANSPIRATION MAPS FOR AUSTRALIA, in: Hydrology and Water Resources Symposium. Institution of Engineers, Melbourne, pp. 2023.

Donohue, R.J., McVicar, T.R., Roderick, M.L. (2010). Assessing the ability of potential evaporation formulations to capture the dynamics in evaporative demand within a changing climate. J. Hydrol. 386, 186-197.

Donohue, R.J., Roderick, M.L., McVicar, T.R. (2008). Deriving consistent long-term vegetation information from AVHRR reflectance data using a cover-triangle-based framework. Remote Sens. Environ. 112, 2938-2949. doi:http://dx.doi.org/10.1016/j.rse.2008.02.008

Frost, A.J., Ramchurn, A., Smith, A. (2016). The Bureau's Operational Landscape (AWRA-L) Model: Technical Description of AWRA-L version 5.

Jeffrey, S.J., Carter, J.O., Moodie, K.B., Beswick, A.R. (2001). Using spatial interpolation to construct a comprehensive archive of Australian climate data. Environ. Model. Softw. 16, 309-330.

Jones, D.A., Wang, W., Fawcett, R. (2007). Climate Data for the Australian Water Availability Project. Final Milestone Report. National Climate Centre, Bureau of Meteorology, Melbourne (Report).

Lim, W.H., Roderick, M.L., Farquhar, G.D. (2016). A mathematical model of pan evaporation under steady state conditions. J. Hydrol. 540, 641-658. doi:10.1016/j.jhydrol.2016.06.048

McMahon, T.A., Peel, M.C., Lowe, L., Srikanthan, R., McVicar, T.R. (2013). Estimating actual, potential, reference crop and pan evaporation using standard meteorological data: a pragmatic synthesis. Hydrol. Earth Syst. Sci. 17, 13311363. doi:10.5194/hess-17-1331-2013

McVicar, T.R., Van Niel, T.G., Li, L.T., Roderick, M.L., Rayner, D.P., Ricciardulli, L., Donohue, R.J. (2008). Wind speed climatology and trends for Australia, 1975-2006: Capturing the stilling phenomenon and comparison with near-surface reanalysis output. Geophys. Res. Lett. 35. doi:10.1029/2008GL035627

Penman, H.L. (1948). Natural Evporation from Open Water, Bare Soil and Grass. R. Soc. 193, 120-145. doi:10.1098/rspa.1948.0037

Rotstayn, L.D., Roderick, M.L., Farquhar, G.D. (2006). A simple pan-evaporation model for analysis of climate simulations: Evaluation over Australia. Geophys. Res. Lett. 33, L17715. doi:10.1029/2006GL027114

Viney, N., Vaze, J., Crosbie, R., Wang, B., Dawes, W., Frost, A. (2015). AWRA-L v5.0: technical description of model algorithms and inputs (Report). CSIRO, Australia.

Walter, I.A., Allen, R.G., Elliott, R., Jensen, M.E., Itenfisu, D., Mecham, B., Howell, T.A., Snyder, R., Brown, P., Echings, S., Spofford, T., Hattendorf, M., Cuenca, R.H., Wright, J.L., Martin, D. (2001). ASCE's Standardized Reference Evapotranspiration Equation, in: Watershed Management and Operations Management 2000. American Society of Civil Engineers, Reston, VA, pp. 1-11. doi:10.1061/40499(2000)126

Wang, Q.J., McConachy, F.L.N., Chiew, F.H.S., James, R., de Hoedt, G.C., Wright, W.J. (2001). Climatic Atlas of Australia - MAPS OF EVAPOTRANSPIRATION (Report). Cooperative Research Centre for Catchment Hydrology, University of Melbourne and Cooperative Research Centre for Catchment Hydrology, Bureau of Meteorology, Melbourne.

Webb, C.P. (2010). Bureau of Meteorology Reference Evapotranspiration Calculations.

Zajaczkowski, J., Wong, K., Carter, J. (2013). Improved historical solar radiation gridded data for Australia. Environ. Model. Softw. 49, 64-77. doi:10.1016/j.envsoft.2013.06.013 